\title{
Disposiciones generales de las Comunidades Autónomas (*)
}

\section{ACADEMIAS}

MUR-1 Ley 2/2005, de 11 de marzo (Presidencia de la Región de Murcia).

Academias de la Región de Murcia.

BOE núm. 118, de 18 de mayo.

BORM núm. 90, de 21 de abril.

\section{AGUAS}

MUR-2 Ley 4/2005, de 14 de junio (Presidencia de la Región de Murcia). Ente Público del Agua.

BOE núm. 130, de 1 de junio.

BORM núm. 162, de 16 de julio.

\section{CÁMARA DE CUENTAS}

AST-2 Ley 3/2006, de 10 de marzo (Presidencia de la Comunidad Autónoma del Principado de Asturias).

Modificación de la Ley 3/2003, de 24 de marzo, de la Sindicatura de Cuentas. BOE núm. 108, de 6 de mayo.

BOPA núm. 63, de 17 de marzo.

\section{CAZA Y PESCA}

BAL-3

Ley 6/2006, de 12 de abril (Presidencia de la Comunidad Autónoma de las Illes Balears).

(*) Sección elaborada por JUAN ANTONIO CARRILLO DONAIRE. Comprende las Leyes y disposiciones con rango de Ley de las Comunidades Autónomas publicadas en el BOE durante el segundo de 2006 (IV-VI). 
Caza y pesca fluvial.

BOE núm. 122, de 23 de mayo.

BOIB núm. 61, de 27 de abril.

CAS-6 Ley 4/2006, de 25 de mayo (Presidencia de la Comunidad Autónoma de Castilla y León).

Modificación de la Ley 4/1996, de 12 de julio, de Caza.

BOE núm. 151, de 26 de junio.

BOCL núm. 110, de 8 de junio.

\section{COLEGIOS PROFESIONALES}

BAL-4 Ley 5/2006, de 30 de marzo (Presidencia de la Comunidad Autónoma de las Illes Balears).

Creación del Colegio Oficial de Terapeutas Ocupacionales.

BOE núm. 113, de 12 de mayo.

BOIB núm. 50, de 6 de abril.

\section{CONSEJO CONSULTIVO}

AST-3

Ley 1/2006, de 16 de febrero (Presidencia de la Comunidad Autónoma del Principado de Asturias).

Modificación del artículo 13.1,k) de la Ley 1/2004, de 21 de octubre, del Consejo Consultivo.

BOE núm. 87, de 12 de abril.

BOPA núm. 47, de 27 de febrero.

VII. CONSEJO ECONÓMICO Y SOCIAL

NAV-8 Ley Foral 2/2006, de 9 de marzo (Presidencia de la Comunidad Foral de Navarra).

Consejo Económico y Social.

BOE núm. 81, de 5 de abril.

BON núm. 33, 17 de marzo.

COOPERATIVAS

NAV-9

Ley Foral 5/2006, de 11 de abril (Presidencia de la Comunidad Foral de Navarra). 
Modificación de la Ley Foral 12/1996, de 2 de julio, de Cooperativas de Navarra, para la adición de la regulación de las cooperativas de iniciativa social.

BOE núm. 113, de 12 de mayo.

BON 50, de 26 de abril.

\section{DEFENSOR DEL PUEBLO}

RIO-5

Ley 6/2006, de 2 de mayo (Presidencia de la Comunidad Autónoma de La Rioja).

Defensor del Pueblo.

BOE núm. 123, de 24 de mayo.

BOLR núm. 59, de 4 de mayo.

\section{DEPORTE}

VAL-8

Ley 3/2006, de 12 de mayo (Presidencia de la Generalitat valenciana).

Creación del Consell Valencià de l'Esport

BOE núm. 154, de 29 de junio.

DOGV núm. 5260, de 17 de mayo.

\section{DERECHO CIVIL FORAL}

CAT-12 Ley 5/2006, de 10 de mayo (Presidencia de la Generalitat de Catalunya).

Libro Quinto del Código Civil de Cataluña, relativo a los derechos reales.

BOE núm. 148, de 22 de junio.

DOGC núm. 4640, de 24 de mayo.

\section{EDIFICACIÓN}

MUR-3 Ley 8/2005, de 14 de diciembre (Presidencia de la Región de Murcia).

Para la calidad en la edificación.

BOE núm. 133, de 5 de junio.

BORM núm. 29, de 4 de febrero. 


\section{EDUCACIÓN}

CAT-13 Ley 3/2006, de 17 de marzo (Presidencia de la Generalitat de Catalunya).

Creación del Fondo de Acción Territorial de la Educación Superior.

BOE núm. 100, de 27 de abril.

DOGC núm. 4304, de 30 de marzo.

BAL-5 Ley 4/2006, de 30 de marzo (Presidencia de la Comunidad Autónoma de las Illes Balears).

Educación y formación permanentes de personas adultas.

BOE núm. 113, de 12 de mayo.

BOIB núm. 50, de 6 de abril.

\section{EMERGENCIAS}

BAL-6

Ley 3/2006, de 30 de marzo (Presidencia de la Comunidad Autónoma de las Illes Balears).

Gestión de emergencias.

BOE núm. 113, de 12 de mayo.

BOIB núm. 50, de 6 de abril.

\section{ESTADÍSTICA}

CAT-14 Ley 2/2006, de 6 de marzo (Presidencia de la Generalitat de Catalunya).

Plan Estadístico de Cataluña 2006-2009.

BOE núm. 82,de 6 de abril.

DOGC núm. 4593, de 15 de marzo.

\section{EXPOSICIÓN UNIVERSAL}

ARA-2 Ley 2/2006, de 6 de abril (Presidencia de la Comunidad Autónoma de Aragón).

Medidas en relación con la Exposición Internacional de Zaragoza de 2008. BOE núm. 104, de 2 de mayo.

BOA núm. 42, de 10 de abril. 


\section{FARMACIAS}

CAN-2 Ley 3/2006, de 20 de marzo (Presidencia de la Comunidad Autónoma de Canarias).

Modificación del artículo 33 de la Ley 4/2005, de 13 de julio, de ordenación farmacéutica.

BOE núm. 117, de 17 de mayo.

BOC núm. 60, de 27 de marzo.

\section{FERROCARRILES}

CAT-15 Ley 4/2006, de 31 de marzo (Presidencia de la Generalitat de

Ferroviaria.

BOE núm. 111, de 10 de mayo.

DOGC núm. 4611, de 10 de abril.

\section{HACIENDA Y SECTOR PÚBLICO}

CAS-3

CAS-7 Ley 2/2006, de 3 de mayo (Presidencia de la Comunidad Autónoma de Castilla y León).

Hacienda y Sector Público.

BOE núm. 135, de 7 de junio.

BOCL núm. número 88 , de 9 de mayo.

\section{INFRAESTRUCTURAS}

NAV-10 Ley Foral 3/2006, de 17 de marzo (Presidencia de la Comunidad Foral de Navarra).

Plan Especial de Infraestructuras Locales para el periodo 2006-2008.

BOE núm. 113, de 12 de mayo.

BON 36, de 24 de marzo.

\section{INVESTIGACIÓN}

RIO-6 Ley 3/2006, de 17 de marzo (Presidencia de la Comunidad Autónoma de La Rioja). 
Creación de la Agencia del Conocimiento y la Tecnología.

BOE núm. 84, de 8 de abril.

BOR núm. 39, de 21 de marzo.

RIO-7 Ley 4/2006, de 19 de abril (Presidencia de la Comunidad Autónoma de La Rioja).

Instituto de Estudios Riojanos.

BOE núm. 118, de 18 de mayo.

BOLR núm. 55, de 25 de abril.

\section{JUVENTUD}

CAS-8

Ley 3/2006, de 25 de mayo (Presidencia de la Comunidad Autónoma de Castilla y León).

Creación del Instituto de la Juventud.

BOE núm. 151, de 26 de junio.

BOCL núm. 110, de 8 de junio.

\section{MEDIACIÓN FAMILIAR}

CAS-9

Ley $1 / 2006$, de 6 de abril (Presidencia de la Comunidad Autónoma de Castilla y León).

Mediación familiar.

BOE núm. 105, de 3 de mayo.

BOCL núm. 75, de 18 de abril.

\section{MEDIDAS ECONÓMICAS}

AST-4 Ley 7/2005, de 29 de diciembre (Presidencia de la Comunidad Autónoma del Principado de Asturias).

Medidas presupuestarias, administrativas y tributarias de acompañamiento a los Presupuestos Generales para 2006.

BOE núm. 83, de 7 de abril.

BOPA núm. 301, de 31 de diciembre.

XXV. MEDIO AMBIENTE

CMN-10 Ley 1/2006, de 23 de marzo (Presidencia de la Comunidad Autónoma de Castilla-La Mancha). 
Creación de la Empresa Pública Gestión Ambiental de Castilla-La Mancha.

BOE núm. 150, de 24 de junio.

VAL-9 Ley 2/2006, de 5 de mayo (Presidencia de la Generalitat valenciana).

Prevención de la contaminación y calidad ambiental

BOE núm. 154, de 29 de junio.

DOGV núm. 5256, de 11 de mayo.

\section{MEDIOS DE COMUNICACIÓN}

AST-5 Ley 2/2006, de 16 de febrero (Presidencia de la Comunidad Autónoma del Principado de Asturias).

Modificación de la Ley 2/2003, de 17 de marzo, de Medios de Comunicación Social.

BOE núm. 87, de 12 de abril.

BOPA núm. 47, de 27 de febrero.

VAL-10 Ley 1/2006, de 19 de abril (Presidencia de la Generalitat valenciana). Sector audiovisual.

BOE núm. 135, de 7 de junio.

DOCV núm. 5243, de 21 de abril.

\section{ORDENACIÓN DEL TERRITORIO Y URBANISMO}

RIO-8 Ley 5/2006, de 2 de mayo (Presidencia de la Comunidad Autónoma de La Rioja).

Ordenación del Territorio y Urbanismo.

BOE núm. 123, de 24 de mayo.

BOLR núm. 59, de 4 de mayo.

\section{PATRIMONIO HISTÓRICO ARTÍSTICO}

BAL-7 Ley 2/2006, de 10 de marzo (Presidencia de la Comunidad

Reforma de la Ley 12/1998, de Patrimonio Histórico.

BOE núm. 88, de 13 de abril.

BOIB núm. núm. 39, de 18 de marzo. 


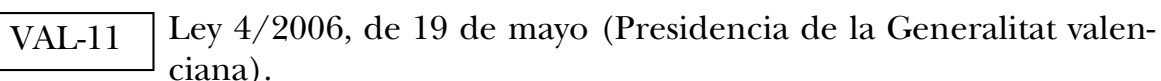

Patrimonio arbóreo monumental.

BOE núm. 154, de 29 de junio.

DOGV núm. 5265, de 24 de mayo.

\section{PRESUPUESTOS}

NAV-11 Ley Foral 1/2006, de 3 de marzo (Presidencia de la Comunidad Foral de Navarra).

Cuentas Generales de Navarra de 2004.

BOE núm. 81, de 5 de abril.

BON núm. 30, de 10 de marzo.

AST-6

Ley 6/2005, de 29 de diciembre (Presidencia de la Comunidad Autónoma del Principado de Asturias).

Presupuestos Generales para 2006.

BOE núm. 83, de 7 de abril.

BOPA núm. 301, de 31 de diciembre.

DRC-4

Ley 2/2006, de 20 de marzo (Presidencia de la Comunidad Autónoma de Cantabria).

Modifica la Ley 5/2005, de 26 de diciembre, de Presupuestos Generales de la Comunidad Autónoma para 2006.

BOE núm. 89, de 14 de abril.

BOC núm. 61, de 28 de marzo.

GAL-3 Ley 9/2005, de 27 de diciembre (Presidencia de la Comunidad Autónoma de Canarias).

Presupuestos Generales para 2006.

BOE núm. 115, de 15 de mayo.

BOC núm. 255, de 30 de diciembre.

MUR-4 Ley 10/2005, de 29 de diciembre (Presidencia de la Región de Murcia).

Presupuestos Generales para 2006.

BOE núm. 135, de 7 de junio.

BORM núm. 301, de 31 de diciembre. 


\section{PUERTOS}

MUR-5

Ley 6/2005, de 1 de julio (Presidencia de la Región de Murcia). Modificación de la Ley 3/1996, de 16 de mayo, de Puertos.

BOE núm. 131, de 2 de junio.

BORM núm. 164, de 19 de julio.

\section{RÉGIMEN LOCAL}

CMN-4 Ley 2/2006, de 7 de febrero (Presidencia de la Comunidad Autónoma de Canarias).

Integración del Cabildo Insular de Lanzarote en el régimen previsto en la Ley $57 / 2003$, de 16 de diciembre, de medidas para la modernización del gobierno local. BOE núm. 117, de 17 de mayo.

BOC núm. 31, de 14 de febrero.

MUR-6 Ley 5/2005, de 20 de junio (Presidencia de la Región de Murcia). Aplicación de la Ley 57/2003, de 16 de diciembre, de medidas para la modernización del gobierno local, a la ciudad de Cartagena.

BOE núm. 131, de 2 de junio.

BORM núm. 163, de 18 de julio.

\section{SUBVENCIONES}

MUR-7

Ley 7/2005, de 18 de noviembre (Presidencia de la Región de Murcia).

Subvenciones.

BOE núm. 133, de 5 de junio.

BORM núm. 278, de 2 de diciembre.

\section{TRIBUTOS}

MUR-8 Ley 9/2005, de 29 de diciembre (Presidencia de la Región de Murcia).

Medidas tributarias en materia de tributos cedidos y tributos propios año 2006.

BOE núm. 134, de 6 de junio.

BORM núm. 301, de 31 de diciembre. 


\section{UNIVERSIDADES}

MUR-9 Ley 3/2005, de 25 de abril (Presidencia de la Región de Murcia). Universidades.

BOE núm. 119, de 19 de mayo.

BORM núm. 106, de 11 de mayo.

\section{VIVIENDA}

CAN-5 Ley 1/2006, de 7 de febrero (Presidencia de la Comunidad Autónoma de Canarias).

Modifica la Ley 2/2003, de 30 de enero, de Vivienda.

BOE núm. 117, de 17 de mayo.

BOC núm. 31, de 14 de febrero.

\section{VOLUNTADES ANTICIPADAS}

BAL-8 Ley 1/2006, de 3 de marzo (Presidencia de la Comunidad Autónoma de las Illes Balears).

Voluntades anticipadas.

BOE núm. 81, de 5 de abril.

BOIB núm. 36, de 11 de marzo.

XXXVII. VOLUNTARIADO

NAV-12

Ley Foral 4/2006, de 4 de abril (Presidencia de la Comunidad Foral de Navarra).

Modifica parcialmente la Ley Foral 2/1998, de 27 de marzo, del Voluntariado. BOE núm. 113, de 12 de mayo.

BON 47, de 19 de abril. 